\title{
Discriminant Analysis and Firms' Bankruptcy: Evidence from European SMEs
}

\author{
Candida Bussoli ${ }^{1}$, Mariateresa Cuoccio ${ }^{1} \&$ Claudio Giannotti ${ }^{2}$ \\ ${ }^{1}$ LUM Jean Monnet University, Italy \\ ${ }^{2}$ LUMSA University, Italy \\ Correspondence: Claudio Giannotti, LUMSA University, Italy. E-mail: c.giannotti@lumsa.it
}

Received: September 19, 2019

Accepted: October 31, 2019 Online Published: November 12, 2019

doi:10.5539/ijbm.v14n12p164

URL: https://doi.org/10.5539/ijbm.v14n12p164

\begin{abstract}
Using two research methodologies - the Altman's z-score discriminant analysis, in the revised version referring to non-listed firms, and the Bayesian approach Diagnostic Distribution - the paper investigates the possibility of discriminating between healthy and bankrupt European SMEs based on financial statements and using a Bayesian discriminant model inspired by Altman's model. It also aims to verify whether the geographic location of European SMEs influences the ability to discriminate between healthy versus bankrupt firms. The work finds a significant homogeneity regarding the capability of the new discriminant models to classify healthy and bankrupt SMEs within the Euro Area and in different geographic locations. The empirical observations confirm that financial statements are a relevant channel by which SMEs communicate information to the financial system, even if they cannot provide all the information that allows for healthy and bankrupt SMEs to be distinguished.
\end{abstract}

Keywords: discriminant analysis, Bayesian analysis, SMEs' bankruptcy

\section{Introduction}

The correct measurement and prediction of firms' credit risk and bankruptcy risk is a topic of great interest for many stakeholders: shareholders, investors, partners, lenders, and regulators. The academic debate on the subject is very topical, and the crisis has increased the number of defaults by firms as well as the attention of banks and supervisory authorities to the topic.

Small and medium-sized enterprises (SMEs) represent more than 99 percent of enterprises in Europe, employing two-thirds of the workforce, and they made a significant contribution to the expansion of the EU-28 economy in recent years. While SMEs are the backbone of the European economy, the Global Financial Crisis has substantially affected the SME sector in Europe. The number of SMEs in the EU-28 increased by $13.8 \%$ between 2008 and 2017; the number of newborn SMEs markedly exceeds the actual increase in the SME population because of the high mortality rate of SMEs, especially among young enterprises (European Commission, 2018). Therefore, bankruptcy continues to be a significant issue affecting them, which means that predicting SME bankruptcy is essential and even more critical after the crises.

The literature on bankruptcy prediction can be divided into three main areas: forecasting models based on accounting data, models based on market data, and models based on artificial intelligence. The models based on accounting data are particularly relevant in countries whose economic system is characterized by the predominance of SMEs, which usually do not resort to capital markets.

The empirical literature on bankruptcy risk forecast for large firms is extensive and has produced a number of bankruptcy prediction models (inter alia: Shumway, 2001; Martin 1977, Ohlson 1980; Altman 1968; Altman et al., 1977; Altman 2000, 2002a, 2013; Zelenkov et al., 2017).

The literature related to SMEs' bankruptcy prediction models is not very extensive. Recent empirical studies emphasize the importance of qualitative factors that may affect the prediction of SME default (Altman \& Sabato 2006, 2007; Fantazzini, De Giuli, Figini, Giudici, 2009); they also explore the diversity within the category of SMEs and the diversity in the accuracy of models (Gupta et al., 2014; Pederzoli et al., 2013; Gordini, 2014).

Our paper contributes to the existing literature related to the use of accounting data. The paper aims to test the impact of the information supplied by financial statements on the assessment of European SMEs' credit risk. The 
paper aims to address two research questions; the first concerns whether it is possible to discriminate between healthy and bankrupt SMEs on the basis of financial statements and a new discriminant model; the second concerns whether the geographic location of European SMEs influences the ability of financial statements to discriminate between healthy firms and bankrupt firms.

The study was carried out for the year 2013, which marks a turning point after the crises, and the sample consists of European SMEs with a significant difference in terms of geographical location and business sectors. The reference sample is made up of European companies; then, we test the predictive capacity of the discriminant models also for weak European countries: Italy, Spain, Portugal, and Greece.

We use two discriminant research methodologies: the z-score discriminant analysis, in the revised version referring to non-listed firms (Altman, 2002b) - it is the comparison tool to test the results of the Bayesian approach - and the Bayesian "Diagnostic distribution" (Aitchison \& Dunsmore, 1975) in a new version, which considers the five variables of the z-score model.

The main results enable us to reiterate the importance of financial statements as a relevant channel of information. Discriminant models have good prediction power, and we find no relevant difference within European SMEs' sub-samples.

The paper is organized as follows. The second section provides a brief review of the literature that leads to the research hypotheses. The third section illustrates the methodology of the research. The fourth section describes the sample, and the fifth discusses the results. The last section includes brief concluding remarks.

\section{Literature Review}

The literature on business failure prediction can be divided into three main areas: forecasting models based on accounting data, models based on market data, and models based on artificial intelligence.

Models based on market data use market information to predict business performance (inter alia: Brockman \& Turtle 2003, Hillegeist et. al 2004, Reisz \% Perlich 2007, Vassalou \& Xing 2004, Carey \& Hrycay 2001): these models can provide useful information, especially where conditions of market efficiency are characterized by semi-strong and strong efficiency.

Many authors have applied the models based on artificial intelligence in many countries (inter alia: Jo \& Han 1996, Etemadi et al. 2009). These models' approaches and techniques have fed a sizeable scientific debate about the operational benefits and practical applications.

The models based on accounting data are particularly relevant in countries whose economic system is characterized by the predominance of small and medium-sized enterprises (SMEs), which usually do not resort to capital markets and are generally financed by the banking system. In this context, corporate financial statements and Central Credit Register are the basis for estimating the probability of default.

There are several limitations inherent to the information in financial statements - arising from conventionality and flexibility of accounting standards and the possibility of determining distorting effects - but they are a useful tool for assessing the reliability of firms regardless if additional information is available.

The use of balance sheet indicators to analyse the creditworthiness of companies dates back to the early twentieth century: it is a univariate approach that examines individual financial ratios. It organizes them into a coherent system of analysis, aiming to understand the weaknesses or strengths of a company and making sectoral comparisons.

The ability to predict the insolvency of enterprises became relevant after the middle of last century when Beaver (1966) elaborated measures based on a dichotomous classification test that allowed for the identification of an optimal cut-off point which can minimize errors of attribution of businesses in two sets, healthy and unhealthy firms.

Beaver showed that accounting data can provide useful information to identify the risk of insolvency or firm bankruptcy and that not all indicators have the same diagnostic capability.

Altman improves the univariate model of Beaver, introducing a multivariate approach, through a discriminant analysis, known as linear discriminant analysis (LDA).

Discriminant analysis is a statistical methodology to classify or make predictions in cases with qualitative dependent variables. It is used to classify an observation and assign it to one of the predefined groups under scrutiny (Sironi and Resti 2008).

Discriminant analysis is used by Altman to develop a model to predict the risk of business failure. Altman's 
z-score is the most famous discriminant score applied to credit risk (Altman, 1968; Altman et al. 1977). The first $z$-score versions were developed for US enterprises in the stock market. Later, this formulation was audited by Altman et al. (1977), who extended the approach by proposing a z-score model that includes a higher number of variables. In the early 2000s, Altman began spelling out a new version of the model for non-listed companies and 'Non-Manufacturers and Emerging Markets' (Altman 2000, 2002a and 2002b).

Recently, other models based on accounting data have been applied in the literature (for a comprehensive review, see Bellovary et al., 2007): Bayesian (Sarkar \& Sriram, 2001, Traczynski, 2017), Hazard (Shumway, 2001), logistic function (Martin, 1977, Ohlson 1980, Becchetti \& Sierra 2003), probit model (Zmijewski, 1984) and Mixed Logit (Jones \& Hensher, 2004).

In particular, the Hazard model (Shumway, 2001) presents an interesting perspective, since it explicitly considers the failure of firms not as a process that occurs at a particular time in the life cycle of enterprises but as a process that takes place during a period in the life of the enterprise. Chava and Jarrow (2004) support this model, arguing that the accounting variables can only slightly improve the predictive power when market variables are included in the prediction model. However, Beaver et al. (2005) emphasize the predictive ability of accounting variables and financial ratios.

The Bayesian model is widely applicable because the estimation is made using several factors, including the relative frequency with which certain kinds of events have occurred in the past. Therefore, the application of Bayesian models is very versatile and effective both for assessing creditworthiness (Kadam and Lenk 2008) and for predicting the risk of insolvency also if compared with other forecasting techniques (Chauduri, 2013).

Philosophov, Batten, and Philosophov (2006), reconsidering a paper originally proposed by Philosophov and Philosophov (2002), investigated the chance of predicting the financial difficulties of enterprises in a number of periods (multi-period bankruptcy prediction). This approach used four financial indices that represent the quantity and quality of debt as well as the ability of the company to repay the debt. The study also used the information obtained from the maturity schedule of a firm's long-term debt to improve the predictions of bankruptcy over long periods. The Bayesian-type model developed in this way uses both kinds of information (ratios and schedule).

Shenoy and Sun (2007) provide a tool for the use of naïve Bayes (a particular form of Bayesian network) to predict the risk of company bankruptcy. In this model, the variables used to predict the risk of bankruptcy are selected with a heuristic method allowing only the variables with a significant correlation with bankruptcy to be selected; using the heuristic method, eight of 20 variables are selected: the eight selected variables allow for an analysis that achieves high accuracy of prediction for both the sample of bankrupt companies and for the sample of non-bankrupt companies.

The empirical literature on modeling credit risk for large enterprises is extensive, and the advancement in methodology has resulted in a substantial increase in the number of bankruptcy prediction models. Research into entrepreneurial failure is increasing, but there remains a lack of clarity related to how failure may be conceptualized (Jenkins \& McKelvie, 2016).

The literature related to SME bankruptcy prediction models is less extensive, but recent empirical studies have improved the understanding of SME behaviour.

Altman and Sabato $(2006,2007)$ use a logistic regression technique for US SMEs and report that their prediction model performs better than credit scoring models. However, they state that the model's performance could be improved by including qualitative information. Altman et al. (2010) reiterate the relevance of non-financial data to supplement the limited accounting data available for non-listed and small firms. They find that data relating to legal action by creditors to recover unpaid debts, company filing histories, comprehensive audit report/opinion data can make a significant contribution to forecasting SME bankruptcy.

Fantazzini, et al. (2009) emphasize the importance of qualitative factors that may affect the prediction of default and propose a Bayesian extension in order to consider both quantitative information (profits, capital structure, cash) and qualitative information (quality of management, moral compensation). They consider that firms can default for some reasons: static factors linked to the characteristics of SMEs, dynamic factors (bank-firm relationship in time), seasonal factors (related to the time investments were made), and external factors (including market trends). They stress the importance of qualitative factors that can influence default predictions and propose a Bayesian extension to the classic models for the prediction of firm's bankruptcy in order to consider the information of a quantitative nature (profits, liquidity, capital structure) and qualitative nature (management quality, moral compensation). 
The recent literature also explores the considerable diversity within the category of small and medium enterprises and the diversity in the accuracy of models.

Gupta et al. (2014) distinguish between micro, small, and medium-sized firms and use both financial and non-financial information to predict a firm's failure hazard. They estimate separate hazard models for each sub-category, and their results suggest that the categories should be considered separately for credit risk modelling purposes. The test results support the hypothesis that the credit risk characteristics of firms within the category of SMEs do vary and suggest that micro firms need to be treated separately.

Pederzoli et al. (2013) develop models that provide estimates of innovative SMEs' PD. Their paper, using logit models, tests whether the PD of innovative firms may be better measured when the model includes indicators related to the balance sheet and variables reflecting the patent portfolio. Specifically, they add two innovation-related variables to a logit model in order to account for the dimension and value of the patent portfolio and show that the value of the patent portfolio reduces the PD, the dimension reduces the firm's riskiness only if coupled with an appropriate equity level.

As for the comparison of different models, Gordini (2014) compares the potential of genetic algorithms (GAs) with those of logistic regression (LR) and support vector machine (SVM), and investigates how the size and the geographical area of firms may influence the accuracy of the models. The results suggest that GAs are very effective instruments in predicting bankruptcy in SMEs compared with LR and SVM. Andreeva et al. (2015) present a cross-country comparison of significant predictors of SME bankruptcy considering several models. They start with the logistic regression, after which they move to Generalised Extreme Value (GEV) regression and the BGEVA model. The results suggest that BGEVA models obtain the best predictive performance.

\section{Theoretical Framework and Research Hypotheses}

Compared to the approaches described above, the present work fits into the literature related to the prediction of business failure based on accounting data and the use of discriminant models.

Scoring models and discriminant analyses can be very subjective and do have limits. One limit is the choice of the sample: samples must be balanced and include the same percentage of successful and bankrupt enterprises. The firms in the examined samples should belong to the same production sector because individual economic and financial indices can differ considerably from sector to sector. Furthermore, if enterprises operate in different production sectors, the incidence of a given index could be different (affecting the estimation of insolvency probabilities).

Another limit is the definition of insolvency. There are different levels of insolvency ranging from delayed payment to complete bankruptcy. The definition of insolvency used to divide the sample affects the results of the analysis. A broad definition of insolvency leads to the definition of a large number of enterprises as insolvent; the assigned probability of default (PD) is, therefore, higher (Sironi \& Resti, 2008).

Independent variables are also a critical issue. The importance and the role of independent variables change with time, according to the structure of markets or the economic cycle (Grice \& Ingramb 2001); it is particularly important in the calculation of the z-score, which has frequently been used by researchers and operators (Berger et al. 1996) long after Altman first used it. The level of accuracy decreases over time because there are changes in the relation between the financial indices used in the model and the economic conditions, which are affected by variable interest rates, inflation, and credit availability (Mensah 1984, Grice \& Ingramb 2001).

Regarding the Bayesian discriminant analysis, the subjective component of the a-priori distribution is particularly critical (Cifarelli \& Muliere 1989).

Bayesian analysis is used to make predictions on firm-related insolvency risk, taking into account empirical experience and integrating quantitative data (especially from financial statements) with data derived from the experience of the subject making the prediction. The concept of probability underlying the Bayesian approach is, therefore, subjective because individuals with different information and expressing opinions based on personal experience will supply different assessments.

Despite the limitations described above, discriminant analysis is one of the most widely used tools to predict the insolvency risk in enterprises. Altman's work is considered a milestone in predicting the risk of business disruption and has stimulated other authors to develop and apply scoring techniques (Inter alia: Choi 2003; Xu \& Zhang 2009, Terdpaopong \& Mihret 2011, Agarwal \& Taffler 2007). Discriminant analysis is also the comparison tool to test the results of other bankruptcy prediction techniques, including logit and probit analyses, neural networks, and Bayesian analysis. 
In this work, we use the Altman model as a tool of comparison but also a starting point for the Bayesian discriminant analysis; the analysis is divided into two levels: the Altman's $z$-score (2002b) and the "Diagnostic distribution". The first level of our analysis concerns the calculation of Altman's z-score, in the revised version, referring to non-listed firms (Altman, 2002b); the model is universally considered as the cornerstone in predicting the bankruptcy of companies, and it is the comparison tool to test the results of the second level of the analysis. The second level concerns a Bayesian approach, i.e., the "Diagnostic distribution" (Aitchison, Dunsmore, 1975).

This work contributes to the literature in seeking to develop a new discriminant analysis - the general Bayesian model is combined with the Altman's model as it uses the five variables of the z-score model (Altman, 2002b) to verify the following research hypotheses:

HP1: It is possible to discriminate between healthy SMEs and unhealthy ones on the basis of financial statements and a new version of the Bayesian discriminant model.

HP2: The geographic location of SMEs within the Euro Area does not affect the possibility of classifying healthy and bankrupt SMEs on the basis of financial statements.

\section{Methodology}

\subsection{Z-Score Analysis}

The first level of analysis concerns the calculation of a summary score that can offer information on the risk of firms defaulting, i.e., the revised $z$-score of Altman (2002b) applied to 2013 financial statements, due to the absence of listed companies in the survey sample.

The use of the revised $z$-score is consistent with the widespread diffusion of credit scoring techniques used by banks to assess the creditworthiness of SMEs (Albareto et al. 2008).

The revised $z$-score formula is shown below.

$$
Z^{\prime}=0.717\left(X_{1}\right)+0.847\left(X_{2}\right)+3.107\left(X_{3}\right)+0.420\left(X_{4}\right)+0.998\left(X_{5}\right)
$$

The function's variables are explained below.

$X_{1}$ : working capital/total assets (WC/TA). This index measures the ratio between liquid assets and the total capitalization of an enterprise. Successful enterprises usually have more liquid assets than struggling enterprises, and this difference increases if the struggling enterprises are almost bankrupt.

$X_{2}$ : retained earnings/total assets (RE/TA). This index provides information on dividend policies. It implicitly considers the company's age and the effect of debt on company management. If this index is high, enterprises have funded their activities with retained earnings and do not need to use much credit.

$X_{3}$ : earnings before interest and taxes / total assets (EBIT/TA). This index measures operating efficiency apart from tax and leveraging factors.

$X_{4}$ : book values of equity / book value of total liabilities (BVE/TL). This index shows how much the value of assets can decrease before liabilities exceed assets, and the company becomes insolvent.

$X_{5}$ : bales / total assets (S/TA). This index shows how much revenue an enterprise can generate through specifically determined assets. It measures the ability of the management to deal with competition in the market in which the enterprise operates.

The accuracy of the revised z-score can be either type I accuracy, concerning the classification of firms approaching bankruptcy as good firms, or type II accuracy, concerning the classification of good firms as bad. The total accuracy of the analysis is the combination of the two. Type I errors are more critical than type II errors because classifying failing enterprises as successful ones lead to considerable expenses for creditors, corresponding to lost capital and interest if the company erroneously considered as creditworthy goes bankrupt. Type II errors are associated with lower costs related to missed earnings caused by denying credit to an enterprise, which is, in fact, successful. Type I errors involve $9.1 \%$ of cases, whereas type II errors involve only $3 \%$ of cases.

According to the revised z-score theory, the higher the value of the $z$-score, the lower the probability of default. The model's cut-off point is 1.23 , and the so-called grey area is between 1.23 and 2.90. In particular, firms with a $z$ value below 1.23 feature a high default risk, while those with a $z$ value above 2.90 have low default risk. Inside the grey area, the model is unable to predict whether the firm is likely to default.

\subsection{Diagnostic Distribution}


The second level of analysis we used in this research is represented by the application of a Bayesian approach to assess the probability of default: "Diagnostic distribution" (Aitchiso \& Dunsmore, 1975). The general Bayesian model considered is explained below.

The symbols and the relevant densities of the diagnostic function are listed below.

1. $T=\{1, \ldots, r\}$ a finite set of possible types. Each case belongs to one (and only one) element of $T$.

2. For each $i$ unit $d$ variables are observed $\left(x_{i 1}, \ldots x_{i d}\right)=x_{i}$ where $i=1, \ldots, n$.

3. The class of probabilistic models regarded as possible functions generating observations (variables) is indexed by a finite-dimension vector $(\psi, \theta)$ with $\psi \in \Psi, \theta \in \Theta$.

$$
\begin{array}{lll}
\text { 4. } & p(t \mid \psi, \theta)=p(t \mid \psi), & (t \in T), \forall \psi \in \Psi, \theta \in \Theta . \\
\text { 5. } & p(x \mid t, \psi, \theta)=p(x \mid t, \theta), & (x \in X), \forall t \in T, \psi \in \Psi, \theta \in \Theta . \\
\text { 6. } & p(z \mid \psi, \theta)=\prod_{n}^{n} p\left(z_{i} \mid \psi, \theta\right), & \forall z=\left(z_{1}, \ldots, z_{n}\right) \text { of case records. } \\
\text { 7. } & p(\psi, \theta)=p(\bar{\psi}) p(\theta) & \psi \in \Psi, \theta \in \Theta .
\end{array}
$$

8. For a new observations vector $u$

$$
p(u \mid \psi)=\psi_{u}(u=1, \ldots, d)
$$

where $\psi_{u}$ represents the $u$ - th component of $\Psi$ and $\Psi=\left\{\psi_{t} \geq 0, \sum_{T} \psi_{t}=1\right\}$ is the $d$-dimensional simplex.

We suppose that we have the case records $z=\left(z_{1}, \ldots, z_{n}\right)$, where $z_{i}=\left(t_{i}, x_{i}\right)$ with $i=1, \ldots, n$, diagnosed cases, $y$ is the vector of data of a new unit, belonging to the unknown category $u$.

Using Bayes theorem for the above mentioned hypotheses, the following formula - known as "diagnostic distribution" - is generated:

$$
p(u \mid y, z)=\frac{p(u \mid t) p(y \mid u, z)}{\sum_{u \in T} p(u \mid t) p(y \mid u, z)}
$$

The distributions of data vectors for each type are considered multinormal i.e.: $N_{d}\left(\mu_{t}, \tau_{t}\right) \forall t ; n_{i}$ is the number of observations belonging to the $i$ category and $n_{1}+\ldots+n_{r}=n \cdot \bar{x}_{t}$ is the vector of averages and $S_{t}$ the variance-covariance matrix of sample. Using the multinormal hypothesis, $m_{t}=\bar{x}_{t}$ and $v_{t}=\left(n_{t}-1\right) S_{t}$ are independent and distributed according to the normal law $N_{d}\left(\mu_{t}, n_{t} \tau_{t}\right)$ and Wishart $W_{d}\left(n_{t}-1, \tau_{t}\right)$. The density of data, considering the type and $z$ data, is of the multivariate T Student kind.

$$
p(y \mid u, z)=S t_{d}\left\{n_{u}-1, m_{u},\left(1+\frac{1}{n_{u}}\right) \frac{v_{u}}{n_{u}-1}\right\}
$$

where

$$
\begin{gathered}
S t_{d}(k, b, c)=\frac{\mathbf{1}}{D\left\{\frac{\mathbf{1}}{\mathbf{2}} \mathbf{1}, \frac{\mathbf{1}}{\mathbf{2}}(k-d+\mathbf{1})\right\}|k c|^{\mathbf{1} / \mathbf{2}}\left\{\mathbf{1}+(u-b)^{\prime}(k c)^{-\mathbf{1}}(u-b)\right\}^{\mathfrak{2}^{(k+1)}}} \\
D(g, h)=\frac{\Gamma\left(g_{1}\right) \ldots \Gamma\left(g_{d}\right) \Gamma(h)}{\Gamma\left(\sum g_{i}+h\right)} \quad\left(g_{i}>\mathbf{0}, \quad i=\mathbf{1}, \ldots, d ; h>\mathbf{0}\right)
\end{gathered}
$$

Applying (1) to our case:

$y$ is the data vector of a new unit.

$u \in\{1,2\}$ represents the category of successful enterprises (1) and failed enterprises (2),

$z$ is the matrix of previously observed data.

$p(y \mid u, z)$ is the likelihood regulating the uncertainty about $y$.

$m_{u}=$ vector of averages. 
$v_{u}=\left(n_{u}-\mathbf{1}\right) S_{u}$ where $S_{u}$ is the variance covariance matrix.

$d=5 \quad$ is the number of variables considered in the model.

$p(u \mid t)=$ a priori probability.

$p(u \mid y, z)=$ a posteriori probability (the probability of a new company to belong to one of the two categories depends on $z$ data and $y$ data).

Two categories were examined, successful enterprises (1) and failed/bankrupt enterprises (2).

As the a priori probability $p(u \mid t)$ were used 0.5 .

\subsection{Sample}

The reference sample is composed of European SMEs with financial statements available in the Amadeus (Bureau Van Dijk) database in August 2016. The enterprises present the following characteristics:

- Legal status: active and independent firms;

- $\quad$ Private limited companies;

- Number of employees less than 250;

- Sales less than fifty million euro;

- Financial statements availability: for the years 2012 and 2013;

- Companies only with unconsolidated accounts.

The study was carried out for the year 2013, which represents the turning point from the crisis years to a slow recovery period for European small and medium-sized enterprises. After the outbreak of the subprime crisis (2008), European SMEs registered an initial 10\% decline in value-added in 2009 and the second decline in 2012. Employment levels of SMEs followed a decline in the period 2008-2013, and only in 2014, a combined increase in employment and value-added of European SMEs was observable (European Commission, 2015). Therefore, 2014 may be considered the real beginning of a slow recovery, and 2013 can be considered a turning year from the crisis. Thus, 2013 is a period of particular interest for studies on the vulnerability of small and medium-sized enterprises weakened by five years of an uncertain and adverse economic environment.

The sample is made up of enterprises from all over Europe that differ significantly in terms of geographical location and business sector based on the NACE classification. Firms that conduct financial activities were not included in the sample.

The starting data analysed in this study to calculate the revised $z$-score and determine the Bayesian model are 139 successful European enterprises that provided financial statements for 2012 and 2013; 139 bankrupt European SMEs have been added to this group. Both samples are obtained through a random extraction from the database.

We then test the predictive capacity of the discriminant models by considering four sub-samples. The sub-samples are made up of SMEs located in peripheral and weak European countries. The evolution of GDP level in Europe (in real terms) varied markedly over the period 2008-2014. The level of real GDP was the same as 2008 in 16 Member States (Austria, Belgium, Bulgaria, Czech Republic, Estonia, France, Germany Ireland, Lithuania, Luxembourg, Malta, Poland, Romania, Slovakia, Sweden, and the United Kingdom). In contrast, the level of GDP in 2014 was below the 2008 level in 12 Member States (Croatia, Cyprus, Denmark, Finland, Greece, Hungary, Latvia, Italy, Netherlands, Portugal, Slovenia, and Spain) (European Commission, 2015). Therefore, we test the predictive capacity of the discriminant models by considering three sub-samples of SMEs from Portugal, Italy, and Spain (peripheral, weak countries) in the case of z-score analysis and four sub-samples of SMEs from Portugal, Italy and Spain and Greece for the Bayesian analysis. We obtained the sub-samples by selecting a random sample of 20 companies for each country.

\section{Results}

For reporting purposes, the results are shown according to the two levels of the survey: z-score analysis and Bayesian analysis.

\subsection{Z-Score Analysis}

The application of the revised z-score (Altman, 2002b) to the entire sample and the four sub-samples in 2013 gives the following results (Table 1). 
Table 1. Revised z-score results

\begin{tabular}{|c|c|c|c|}
\hline & High risk & Grey Area & Low risk \\
\hline Healthy European SMEs & $17.99 \%$ & $51.80 \%$ & $30.22 \%$ \\
\hline Bankrupt European SMEs & $70.50 \%$ & $24.46 \%$ & $5.04 \%$ \\
\hline Healthy Italian SMEs & $30.77 \%$ & $57.69 \%$ & $11.54 \%$ \\
\hline Bankrupt Italian SMEs & $84.62 \%$ & $11.54 \%$ & $3.85 \%$ \\
\hline Healthy Spanish SMEs & $11.54 \%$ & $46.15 \%$ & $42.31 \%$ \\
\hline Bankrupt Spanish SMEs & $65.38 \%$ & $34.62 \%$ & $0.00 \%$ \\
\hline Healthy Portuguese SMEs & $11.76 \%$ & $58.82 \%$ & $29.42 \%$ \\
\hline Bankrupt Portuguese SMEs & $72.55 \%$ & $23.53 \%$ & $3.92 \%$ \\
\hline Healthy European SMEs from weak countries & $16.50 \%$ & $55.34 \%$ & $28.16 \%$ \\
\hline Bankrupt European SMEs from weak countries & $73.79 \%$ & $23.30 \%$ & $2.91 \%$ \\
\hline
\end{tabular}

For successful European SMEs, the median value is 2.23, and the average is 3.03. The analysis highlights that $30.22 \%$ of firms featured a low default risk, while $17.99 \%$ featured a very high risk; $51.80 \%$ of firms are in the grey area.

For bankrupt European SMEs, the median value is 0.47 , and the average is -1.26 . The analysis highlights that $5.04 \%$ of firms featured a low default risk, while $70.50 \%$ featured a very high risk; $24.46 \%$ of firms are in the grey area.

Regarding the four sub-samples referring to the weak countries, the results are as follows.

For successful Italian SMEs, the median value is 1.74 , and the average is 1.91 . The analysis highlights that $11.54 \%$ of firms featured a low default risk, while $30.77 \%$ featured a high risk; $57.69 \%$ of firms are in the grey area. For bankrupt Italian SMEs, the median value is -0.01 , and the average is -1.61 . The analysis highlights that $3.85 \%$ of firms featured a low default risk, while $84.62 \%$ featured a high risk; $11.54 \%$ of firms are in the grey area.

Regarding bankrupt enterprises, the results are relevant. Type I errors relating to the possibility of considering erroneously bankrupt firms as creditworthy only affects $3.85 \%$ of the sample related to Italian SMEs and $5.04 \%$ of the sample related to Europe; this is a meaningful result as type I errors are more critical than type II errors.

Regarding healthy companies, the predictive ability of the model is less satisfactory: the type II error, related to the classification of healthy companies as bankrupt, affects $30.77 \%$ of Italian enterprises and $17.99 \%$ of European enterprises. In the case of healthy firms, the grey area - in which the model is unable to predict whether the firm is likely to default or not - is also wide.

For successful Spanish SMEs, the median value is 2.41 , and the average is 2.74 . The analysis highlights that $42.31 \%$ of firms featured a low default risk, while $11.54 \%$ featured a high risk; $46.15 \%$ of firms are in the grey area. For bankrupt Spanish SMEs, the median value is 0.69 , and the average is 0.57 . The analysis highlights that $0 \%$ of firms featured a low default risk, while $65.38 \%$ featured a high risk; $34.62 \%$ of firms are in the grey area.

For successful Portuguese SMEs, the median value is 2.40 , and the average is 3.95 . The analysis highlights that $29.42 \%$ of firms featured a low default risk, while $11.76 \%$ featured a high risk; $58.82 \%$ of firms are in the grey area. For bankrupt Portuguese SMEs, the median value is 0.34 , and the average is -0.33 . The analysis highlights that $3.92 \%$ of firms featured a low default risk, while $72.55 \%$ featured a high risk; $23.53 \%$ of firms are in the grey area.

For healthy European SMEs from weak countries considered jointly, the median value is 2.23 , and the average is 3.13. The analysis highlights that $28.16 \%$ of firms featured a low default risk, while $16.50 \%$ featured a very high risk; $73.79 \%$ of firms are in the grey area. For bankrupt European SMEs from weak countries, the median value is 0.34 , and the average is -0.43 . The analysis highlights that $2.91 \%$ of firms featured a low default risk, while $16.50 \%$ featured a very high risk; $23.30 \%$ of firms are in the grey area.

The z-score discriminant analysis (Altman, 2002b) allows to discriminate between healthy SMEs and unhealthy ones on the basis of financial statements, and the geographic location of SMEs within the Euro Zone does not influence the reliability of financial statements and the ability to discriminate between healthy firms and bankrupt firms. 


\subsection{Bayesian Analysis}

Regarding the Bayesian analysis, we have built the model using the (1) and using the five variables of the z-score model (Altman, 2002b). This model has been tested on the reference sample to distinguish all the firms as either successful and bankrupt.

The model then discriminates any element of the reference sample using the following rule:

- If $p(1 \mid y, z)>0.95$ the model will rank the firm as healthy.

- If $p(1 \mid y, z) \leq 0.95$ the model will rank the firm as bankrupt.

After fixing the probability of default for each firm, we compared it with the real status of that firm.

According to this method, we have obtained the following result for European firms:

- Correctly classified successful firms: $76.26 \%$.

- Correctly classified bankrupt firms: $80.58 \%$.

We then tested the predictive capacity of the Bayesian model on four sub-samples related to healthy European SMEs from weak countries: Italy, Spain, Portugal. We obtained the sub-samples by selecting a random sample of 20 companies for each country. The results are as follows.

Healthy Italian SMEs, correctly classified successful firms: $70.00 \%$.

Healthy Portuguese SMEs, correctly classified successful firms: $70.00 \%$.

Healthy Spanish SMEs, correctly classified successful firms: $70.00 \%$.

Healthy Greek SMEs, correctly classified successful firms: $85.00 \%$

Healthy European SMEs from weak countries, jointly considering the values of the four weakest countries, correctly classified successful firms: $73.75 \%$.

\section{Discussion}

Based on the results, it is possible to observe that both research hypotheses are verified. It is possible to discriminate healthy companies from failed ones, based on the Bayesian discriminant analysis model constructed using the financial variables of the Altman model. The Bayesian approach allows us to correctly classify SMEs, with a percentage of $76.26 \%$, and bankrupt firms with a percentage of $80.58 \%$. The results confirm, in line with the reference literature, and supported by the results of the Altman model, the predictive utility of the balance sheet data.

The Bayesian discriminant analysis model, however, presents the limit of the choice of the a priori distribution, which presents a strong subjective component. In the new model used, as the a priori probability $p(u / t)$ is used 0.5 .

The weakness of the model, identified in the subjective component of the a priori distribution, represents, however, also the direction to improve the predictive capacity of the balance sheet data. Indeed, a better evaluation of the a priori distribution, also through the use of soft information, could allow a more accurate predictive ability.

The second research hypothesis is also verified, and the analysis, therefore, has a high capacity to discriminate between healthy and bankrupt companies even in countries with weaker economic and financial conditions. In this case also the weakness of the subjectivity of the a priori distribution remains, but the wide possibility to improve its predictive capacity is confirmed. Indeed the predictive capacity could be improved through information relative to endogenous and exogenous conditions of companies, such as forecasts on the economic situation and the efficiency of the financial system on the one hand and the strategic vision of the company, the degree of internationalization and the governance structures of the company on the other. Such valuable information could be incorporated in the model through an ad hoc definition of the a priori distribution.

\section{Conclusion}

The paper has tested the possibility of discriminating between healthy and bankrupt European SMEs on the basis of the financial statements for the year 2013 and a new Bayesian discriminant model.

The main results allow us to reiterate the importance of financial statements to classify the firms, but in different ways and with different accuracy, depending on the model used.

The revised z-score is able to successfully discriminate defaulting firms in the case of $70.50 \%$ with low type I errors. On the other hand, it properly considers a smaller percentage of healthy firms . 
The Bayesian approach allows us to correctly classify healthy SMEs, with a percentage of $76.26 \%$, and bankrupt firms with a percentage of $80.58 \%$.

We find significant homogeneity regarding the capability of the models to classify healthy and bankrupt SMEs on the basis of financial statements within the four European sub-samples (i.e., Italy, Portugal, Spain, and Greece). The z-score analysis is able to successfully discriminate defaulting firms in the case of $73.79 \%$ of firms; in this case, it also properly considers a smaller percentage of healthy firms. The Bayesian approach allows us to correctly classify healthy SMEs, with a percentage of $73.75 \%$.

The empirical observation reiterates the importance of the financial statements as a main channel of information by firms to the financial system and affirms the effectiveness of the new Bayesian discriminant model.

However, the predictive ability made only on sheet data is not error-free, which leads to the assumption that financial statements cannot provide all the information that allows us to distinguish between healthy and bankrupt SMEs. Soft information can be incorporated into the model through an ad hoc definition of the a priori distribution, improving its predictive capacity.

\section{References}

Agarwal, V., \& Taffler, R. J. (2007). Twenty-five years of the Taffler z-score model: does it really have predictive ability? Accounting and Business Research, 17(4), 285-300. https://doi.org/10.1080/00014788.2007.9663313

Aitchison, J., \& Dunsmore, I. R. (1975). Statistical Prediction Analysis. Cambridge University Press. https://doi.org/10.1017/CBO9780511569647

Albareto, G., Benvenuti, M., Mocetti, S., Pagnini, M., \& Rossi, P. (2008). Lending organizational structure and the use of credit scoring: evidence from a survey on Italian banks. Bank of Italy, Occasional Papers, 12.

Altman, E. I. (1968). Financial Ratios, Discriminant Analysis and the Prediction of Corporate bankruptcy. Journal of Finance, 23(4), 589-609. http://dx.doi.org/10.1111/j.1540-6261.1968.tb00843.x

Altman, E. I. (2000). Predicting Financial Distress of Companies: Revisiting the Z-Score and ZETA ${ }^{\circledR}$ Models. Working Paper New York University, July.

Altman, E. I. (2002a). Bankruptcy credit risk and high yield junk bonds. Blackwell Publishing, Inc, Malden.

Altman, E. I. (2002b). Revisiting credit scoring models in a Basel 2 environment. In Ong, M. (Ed.), Credit Rating: Methodologies, Rationale and Default Risk. London Risk Books.

Altman, E. I. (2013). Predicting financial distress of companies: revisiting the Z-Score and ZETA $®$ models. In Handbook of Research Methods and Applications in Empirical Finance. Edward Elgar Publishing.

Altman, E. I., \& Sabato, G. (2007). Modeling credit risk for SMEs: evidence from the US market. Abacus, 43, 332-357. https://doi.org/10.1111/j.1467-6281.2007.00234.x

Altman, E. I., Haldeman, R., \& Narayanan, P. (1977). Zeta Analysis: A New Model to Identify bankruptcy Risk of Corporations. Journal of Banking \& Finance, 1(1), 29-54. https://doi.org/10.1016/0378-4266(77)90017-6

Altman, E. I., Sabato, G., \& Wilson, N. (2010). The Value of Non-Financial Information in Small and Medium-Sized Enterprise Risk Management. The Journal of Credit Risk, 6(2), 95-127. https://doi.org/10.21314/JCR.2010.110

Andreeva, G., Calabrese, R., \& Osmetti, S. A. (2015). A comparative analysis of the UK and Italian small businesses using Generalised Extreme Value models. European Journal of Operational Research, 1-11. https://doi.org/10.1016/j.ejor.2015.07.062

Beaver, W. (1966). Financial ratios as predictors of failure. Journal of Accounting Research, 4, 71-111. https://doi.org/10.2307/2490171

Beaver, W. H., McNichols, M. F., \& Rhie, J. W. (2005). Have Financial Statements Become Less Informative? Evidence from the Ability of Financial Ratios to Predict Bankruptcy. Review of Accounting Studies, 10, 93-122. https://doi.org/10.1007/s11142-004-6341-9

Becchetti, L., \& Sierra, J. (2003). Bankruptcy Risk and Productive Efficiency in Manufacturing Firms. Journal of Banking \& Finance, 27, 2099-2120. https://doi.org/10.1016/S0378-4266(02)00319-9

Begley, J. Ming, J. Watts, S. (1996). Bankruptcy classification errors in the 1980s: an empirical analysis of Altman's and Ohlson's models. Review of Accounting Studies, 1(4), 267-284. https://doi.org/10.1007/BF00570833 
Bellovary, J., Giacomino, D., \& Akers, M. (2007). A Review of Bankruptcy Prediction Studies: 1930 to Present. Journal of Financial Education, 33, 1-43. Retrieved from https://epublications.marquette.edu/account_fac/25

Berger, P. E., Ofek, E., \& Swary, I. (1996). Investor valuation of the abandonment option. Journal of Financial Economics, 42(2), 257-287. https://doi.org/10.1016/0304-405X(96)00877-X

Brockman, P., \& Turtle, H. (2003). A barrier option framework for corporate security valuation. Journal of Financial Economics, 67(3), 511-529. https://doi.org/10.1016/S0304-405X(02)00260-X

Carey, M. Hrycay, M. (2001). Parameterizing credit risk models with rating data. Journal of Banking \& Finance, 25(1), 197-270. https://doi.org/10.1016/S0378-4266(00)00124-2

Chaudhuri, A. (2013). Bankruptcy Prediction Using Bayesian, Hazard, Mixed Logit and Rough Bayesian Models: A Comparative Analysis. Computer and Information Science, 6(2), 104-125. https://doi.org/10.5539/cis.v6n2p103.

Chava, S., \& Jarrow, R. (2004). Bankruptcy prediction with industry effect, market versus accounting variables, and reduced form of credit risk models. Review of Finance, 8(4), 537-569. https://doi.org/10.1093/rof/8.4.537

Choi, F. D. S. (2003). International finance and accounting handbook. John Wiley \& sons, inc., New Jersey.

Cifarelli, D. M., \& Muliere, P. (1989). Statistica Bayesiana. Gianni Iuculano Editore. Pavia.

Cifarelli, D. M., Corielli, F., \& Forestieri, G. (1988). Business Failure Analysis. A Bayesian Approach with Italian Firm Data. Studies in Banking \& Finance, 7, 73-89.

Etemadi, H., Rostamy, A., \& Dehkordi, H. (2009). A genetic programming model for bankruptcy prediction: empirical evidence from Iran. Expert Systems with Applications, 36(2), 3199-3207. https://doi.org/10.1016/j.eswa.2008.01.012

European Commission. (2015). Annual Report on European SMEs 2014

European Commission. (2018). Annual Report on European SMEs 2017-2018.

Fantazzini, D., De Giuli, M. E., Figini, S., \& Giudici, P. (2009). Enhanced credit default models for heterogeneous SME segments. Journal of Financial Transformation, 25, 31-39.

Gordini, N. (2014). A genetic algorithm approach for SMEs bankruptcy prediction: Empirical evidence from Italy. Expert Systems with Applications, 41(14), 6433-6445. https://doi.org/10.1016/j.eswa.2014.04.026

Grice, J. S., \& Ingramb, R. W. (2001). Tests of the generalizability of Altman s bankruptcy prediction model. Journal of Business Research, 54, 53-61. https://doi.org/10.1016/S0148-2963(00)00126-0

Gupta, J., Gregoriou, A., \& Healy J. (2015). Forecasting bankruptcy for SMEs using hazard function: To what extent does size matter? Review of Quantitative Finance and Accounting, 45(4), 845-869. https://doi.org/10.1007/s11156-014-0458-0

Hillegeist, S., Keating, E., Cram, D., \& Lundstedt, K. (2004). Assessing the probability of bankruptcy. Review of Accounting Studies, 9(1), 5-34. https://doi.org/10.1023/B:RAST.0000013627.90884.b7

Jenkins, A., \& McKelvie, A. (2016). What is entrepreneurial failure? Implications for future research. International Small Business Journal, 34, 176-188. https://doi.org/10.1177/0266242615574011

Jo, H., \& Han, I. (1996). Integration of case-based forecasting, neural network, and discriminant analysis for bankruptcy prediction. Expert Systems with Applications, 11(4), 415-422. https://doi.org/10.1016/S0957-4174(96)00056-5

Jones, S., \& Hensher, D. A. (2004). Predicting Firm Financial Distress: A Mixed Logit Model. The Accounting Review, 79(4), 1011-1038. https://doi.org/10.2308/accr.2004.79.4.1011

Kadam, A., \& Lenk, P. (2008). Bayesian Inference for Issuer Heterogeneity in Credit Ratings Migration. Journal of Banking \& Finance, 32(10), 2267-2274. https://doi.org/10.1016/j.jbankfin.2007.12.043

Martin, D. (1977). Early Warning of Bank Failure: a logit regression approach. Journal of Banking and Finance, 1, 249-276. https://doi.org/10.1016/0378-4266(77)90022-X

Mensah, Y. M. (1984). An examination of the stationarity of multivariate bankruptcy prediction models: a methodological study. Journal of Accounting Research, 22(1), 380-395. https://doi.org/10.2307/2490719

Min, J., \& Jeong, C. (2009). A binary classification method for bankruptcy prediction. Expert Systems with 
Applications, 36(3), 5256-5263. https://doi.org/10.1016/j.eswa.2008.06.073

Ohlson, J. A. (1980). Financial Ratios and the Probabilistic Prediction of Bankruptcy. Journal of Accounting Research, 18(1), 109-131. https://doi.org/10.2307/2490395

Pederzoli, C., Thoma, G., \& Torricelli, C. (2013). Modelling Credit Risk for Innovative SMEs: the Role of Innovation Measures. Journal of Financial Services Research, 44, 111-129. https://doi.org/10.1007/s10693-012-0152-0

Philosophov, L. V., Batten, J. A., \& Philosophov, V. L. (2006). Multi-period Bayesian Bankruptcy Prediction Using Financial Ratios and the Maturity Schedule of Long-Term Debt. Retrieved from http://www.aha.ru/ soliton/english/articles/MBPT.pdf

Philosophov, L., \& Philosophov, V. (2002). Corporate bankruptcy prognosis: An attempt at a combined prediction of the bankruptcy event and time interval of its occurrence. International Review of Financial Analysis, 11, 375-406. https://doi.org/10.1016/S1057-5219(02)00081-9

Platt, H. D., \& Platt, M. B. (1991). A note on the use of industry-relative ratios in bankruptcy prediction. Journal of Banking and Finance, 15(6), 1183-1194. https://doi.org/10.1016/0378-4266(91)90057-S

Reisz, A., \& Perlich, C. (2007). A market-based framework for bankruptcy prediction. Journal of Financial Stability, 3(2), 85-131. https://doi.org/10.1016/j.jfs.2007.02.001

Ribeiro, M. S., Pina, J. P., Soares, J., \& Lopes, M. C. (2011). Quantitative vs. Qualitative Criteria for Credit Risk Assessment. Frontiers in Finance and Economics, 8(1), 69-87. https://dx.doi.org/10.2139/ssrn.2012443

Sarkar, S., \& Sriram, R. S. (2001). Bayesian Models for Early Warning of Bank Failures. Management Science, 47(11), 1457-1475. https://doi.org/10.1287/mnsc.47.11.1457.10253

Shenoy, P. P., \& Sun, L. (2007). Using Bayesian Networks for Bankruptcy Prediction: Some Methodological Issues. European Journal of Operational Research, 180, 738-753. https://doi.org/10.1016/j.ejor.2006.04.019

Shumway, T. (2001). Forecasting bankruptcy more accurately: A simple hazard model. Journal of Business, 74, 101-124. http://dx.doi.org/10.1086/209665

Sironi, A., \& Resti A. (2008). Rischio e valore nelle banche: Risk management e capital allocation. EGEA, Milano.

Stefanescu, C., Tunaru, R., \& Turnbull, S. (2009). The credit rating process and estimation of transition probabilities: A Bayesian approach. Journal of Empirical Finance, 16(2), 216-234. https://doi.org/10.1016/j.jempfin.2008.10.006

Terdpaopong, K., \& Mihret, D. G. (2011). Modelling SME credit risk: Thai empirical evidence. Small Enterprise Research, 18, 63-79. https://doi.org/10.5172/ser.18.1.63

Traczynski, J. (2017). Firm Default Prediction: A Bayesian Model-Averaging Approach. https://doi.org/10.1017/S002210901700031X

Vassalou, M., \& Xing, Y. (2004). Default risk in equity returns. The Journal of Finance, 59(2), 831-868. https://doi.org/10.1111/j.1540-6261.2004.00650.x

Xu, M., \& Zhang, C. (2009). Bankruptcy prediction: the case of Japanese listed companies. Review of Accounting Studies, 14, 534-558. http://hdl.handle.net/1783.1/17659

Zelenkov, Y., Fedorova, E., \& Chekrizov, D. (2017). Two-step classification method based on genetic algorithm for bankruptcy forecasting. Expert Systems with Applications, 88, 393-401. https://doi.org/10.1016/j.eswa.2017.07.025

Zhang, J. L., \& Härdleb, W. K. (2010). The Bayesian Additive Classification Tree applied to credit risk modeling. Computational Statistics \& Data Analysis, 54(5), 1197-1205. https://doi.org/10.1016/j.csda.2009.11.022

Zmijewski, M. E. (1984), Methodological Issues Related to the Estimation of Financial Distress Prediction Models. Journal of Accounting Research, 22, 59-82. https://www.jstor.org/stable/2490859

\section{Copyrights}

Copyright for this article is retained by the author(s), with first publication rights granted to the journal.

This is an open-access article distributed under the terms and conditions of the Creative Commons Attribution license (http://creativecommons.org/licenses/by/4.0/). 